Old Dominion University

ODU Digital Commons

VMASC Publications

Virginia Modeling, Analysis \& Simulation Center

2012

\title{
A System Dynamics Model for Simulating Ambulatory Health Care Demands
}

Rafael Diaz

Old Dominion University, rdiaz@odu.edu

Joshua G. Behr

Old Dominion University, jbehr@odu.edu

Mandar Tulpule

Follow this and additional works at: https://digitalcommons.odu.edu/vmasc_pubs

Part of the Health Economics Commons, Operational Research Commons, and the Public Health Commons

\section{Repository Citation}

Diaz, Rafael; Behr, Joshua G.; and Tulpule, Mandar, "A System Dynamics Model for Simulating Ambulatory Health Care Demands" (2012). VMASC Publications. 20.

https://digitalcommons.odu.edu/vmasc_pubs/20

\section{Original Publication Citation}

Diaz, R., Behr, J. G., \& Tulpule, M. (2012). A system dynamics model for simulating ambulatory health care demands. Simulation in Healthcare, 7(4), 243-250. doi:10.1097/SIH.0b013e318259d134

This Article is brought to you for free and open access by the Virginia Modeling, Analysis \& Simulation Center at ODU Digital Commons. It has been accepted for inclusion in VMASC Publications by an authorized administrator of ODU Digital Commons. For more information, please contact digitalcommons@odu.edu. 


\section{A System Dynamics Model for Simulating Ambulatory Health Care Demands}

\begin{abstract}
Rafael Diaz, PhD; Introduction: This article demonstrates the utility of the system dynamics approach to model and simulate US demand for ambulatory health care service both for the general population and for specific cohort subpopulations over the 5-year period, from 2003 to 2008. A system dynamics approach that is shown to meaningfully project demand for services has implications for health resource planning and for generating knowledge that is critical to assessing interventions.

Methods: The study uses a cohort-component method in combination with structural modeling to simulate ambulatory health care utilization. Data are drawn from the National Ambulatory Medical Care Survey and the National Hospital Ambulatory Medical Care Survey.

Results: The simulation of the total population requiring ambulatory services between 2003 and 2008 is performed to test the functionality and validate the model. Results show a close agreement between the simulated and actual data; the percent error between the two is relatively low, $1.5 \%$ on average. In addition, simulations of purposively selected population subsets are executed (men, 18-24 years of age, white, African American, Hispanic, and insurance coverage), resulting in error between simulated and actual data, which is $7.05 \%$ on average.

Conclusions: The proposed model demonstrates that it is possible to represent and mimic, with reasonable accuracy, the demand for health care services by the total ambulatory population and the demand by selected population subsets. This model and its simulation demonstrate how these techniques can be used to identify disparities among population subsets and a vehicle to test the impact of health care interventions on ambulatory utilization. A system dynamics approach may be a useful tool for policy and strategic planners.
\end{abstract}

(Sim Healthcare 7:243-250, 2012)

Key Words: Population modeling, system dynamics, health care resource planning. he demand for ambulatory health care services varies across subgroups within the general US population. Vulnerable populations, particularly infants and senior citizens, tend to use more ambulatory health care resources relative to other population segments. Females relative to males also use more ambulatory health care resources. ${ }^{1}$ There is also variation in demand for ambulatory health care services based on race, ethnicity, and insurance status. ${ }^{2-8}$ The quality of a health care system is measured, in part, by the flexibility of the supply side of the health care services, particularly human resources, to respond to the demand for services. ${ }^{9}$ For example, emergency department waiting times and throughput are associated with the availability of nursing staff and administrative support personnel, ${ }^{10,11}$ and the forecasting of anesthesia workload in operating rooms may require knowledge of the geographic area served by the hospital. ${ }^{12}$

From the Virginia Modeling, Analysis and Simulation Center, Old Dominion University, Norfolk, VA.

The authors declare no conflict of interest.

Reprints: Rafael Diaz, PhD, Virginia Modeling, Analysis and Simulation Center, Old Dominion University, 1030 University Blvd, Suffolk, VA 23435

(e-mail: rdiaz@odu.edu).

Copyright (C) 2012 Society for Simulation in Healthcare

DOI: $10.1097 /$ SIH.0b013e318259d134
Strategic and operational planning of health care systems requires an understanding of general population dynamics. Public policy makers must craft policy in the context of evolving populations, ${ }^{13,14}$ and health care institutions must forecast demand in an effort to match supply. ${ }^{15} \mathrm{Al}$ though estimating overall aggregate demand for ambulatory services is useful, disaggregated projections are more desirable because they may illuminate the disparities in utilization among population segments $s^{8,9}$ and as such may allow planners to assess the impact of interventions on particular patient subpopulations.

Population models may focus on the supply side, the demand side, or some combination of both. ${ }^{9,16}$ Demandcentric models forecast the size and needs of populations. Supply-centric models predict future availability of the health care workforce, which is itself influenced by broader population changes because these trends affect the potential workforce entering into health care fields. Thus, population trends not only influence the demand directly but also affect the supply indirectly. ${ }^{17,18}$ Independent of the model choice, population modeling is an inherent requirement for reasonable projection of health care needs.

Times series techniques are commonly used to forecast population trends. These techniques have some limitations, however. First, time series have difficulty capturing dynamic 
behavior of populations such as a reversal in the direction of the death rate. ${ }^{15}$ Second, they assume a permanent limit to the modeled variables. Third, time series have difficulty assessing the impact of interventions or producing projections for specific subgroups. ${ }^{19}$ For example, several score of permutations in population subgroups may be derived from several variables such as sex, age, race, and ethnicity.

This article offers an instructive illustration of system dynamics as an approach to assist in both resource and intervention planning, which may be used in ambulatory health care environments. The system dynamics approach, grounded in control theory and the modern theory of nonlinear dynamics, is a modeling method to characterize the behavior of complex systems over time. ${ }^{20}$ It involves capturing the system behavior from feedback loops and time delays. Both causal loop and stocks and flows diagram tools help characterize how the system's elements relate and interact to one another.

The strength of system dynamics modeling is found in the ability to capture the complexities associated with structural components such as birth and death rates. System dynamics is able to represent the complexities inherent in the health care system due to subpopulations with different demands and can then project the ambulatory health care utilization of these subpopulations. System dynamics is an appropriate approach specifically because it is best able to represent the dynamics that are inherent in the considered complex system. Relative to other, more traditional approaches, such as linear regression, system dynamics is more flexible in considering feedback effects and analyzing the dynamic changes in behavior stemming from various dissimilar sources.

\section{HEALTH CARE AND POPULATION MODELING}

There are various population models for health care human resource planning and forecasting. O'Brien-Pallas et $\mathrm{al}^{9}$ provide an accessible review of various modeling approaches used in forecasting human resource requirements in health care. Other literature reviews include the works of Willekens, ${ }^{21}$ Wilson and Phil, ${ }^{22}$ Booth, ${ }^{23}$ and O'Neill et al. ${ }^{15}$ Often, frameworks use a manpower-to-population projection ratio. ${ }^{9,18,24}$ Some frameworks focus on determining availability and characteristics of the workforce ${ }^{9}$ in addition to projecting manpower beyond that which is required to obtain a given service level. ${ }^{18}$ Roberfroid et al ${ }^{18}$ propose a framework that simultaneously considers both the demand and the supply. Dubois et $\mathrm{al}^{17}$ consider supply and demand in the context of globalization. Birch et $\mathrm{al}^{13}$ model health care demand as needs rather than simply utilization. They used a time horizon of 40 years to project the number of registered nurse needed. These authors remark that, on one hand, the aging population is increasing the demand for health care whereas, on the other hand, a shrinking working class is putting pressure on workforce availability. Thus, demographic trends not only influence the demand directly but also affect the supply indirectly. This reinforces the need for modeling efforts to represent the dynamics of demographic components. ${ }^{18}$

\section{COHORT COMPONENT MODELING AND STRUCTURAL MODELING}

Two techniques for population modeling central to this article include the cohort-component and structural models. Other methods for population projection include common time series approaches that extrapolate past change processes $^{15,23}$ and microsimulation methods analogous to sampling methods. ${ }^{22}$

The cohort-component method relies on dividing the subject population into groups based on primary characteristics, particularly age and sex. ${ }^{15,25-29}$ Multistate cohort-component methods extend this to include other demographic features such as educational and marital status. Cohort-component modeling mathematically expresses in a set linear equations the future age distribution of a population given the present age distribution. ${ }^{30}$ In this article, each equation expresses the number of people advancing to another age group as a product of the present population and the probability of survival. The summation of offspring produced in each age group multiplied by the probability of their survival serves as the input to the first age group. Cohort-component methods may draw on vital birth and death records and analysis of past forecasting errors or rely on less tangible "expert opinion." ${ }^{15,22,31}$ Nonetheless, establishing the sizes of the initial stocks is critical sources of uncertainty in this type of model.

Structural models, such as system dynamics models, place an emphasis on characterizing the casual relationships between birth and death rates (and other socioeconomic factors) to explain demographic trends. An overview of structural models is given by Sanderson. ${ }^{32}$ Within the simulation field, the regarded works of Meadows et al, ${ }^{33}$ drawing heavily on the study of Forrester ${ }^{34}$; Mohapatra et $\mathrm{a}^{35}$; and Azeem Qureshi ${ }^{36}$ involve system dynamics modeling, a form of structural modeling, for population growth and humanresource planning. Cohen ${ }^{37}$ argues that projection of birth and deaths is difficult; population models are inherently complex, and longer-term forecasts may be quite sensitive to early assumptions and perturbations. The rates of birth and death over time, for example, may have a seasonal or cyclical component due to broader cultural or economic shifts. In addition, immigration may impact both demand for and supply of health care services. In addition, some models either do not have theoretical underpinnings or are not informed by real-world data. ${ }^{38}$

\section{METHODOLOGICAL FRAMEWORK}

The system dynamics framework acknowledges the complex interactions among many feedback loops, accounts for linear and nonlinear cause-and-effect relationship, and considers the potential impact of effects on causes. We follow a general modeling methodology widely used and proposed by Sterman $^{20}$ : (1) specify the ambulatory population model, (2) identify theory that girds the model, (3) test the dynamic hypotheses by way of simulation, (4) analyze the impact of health care interventions that influence on system behavior, and (5) further calibrating and test the model. The ambulatory population model is first conceptually illustrated by 


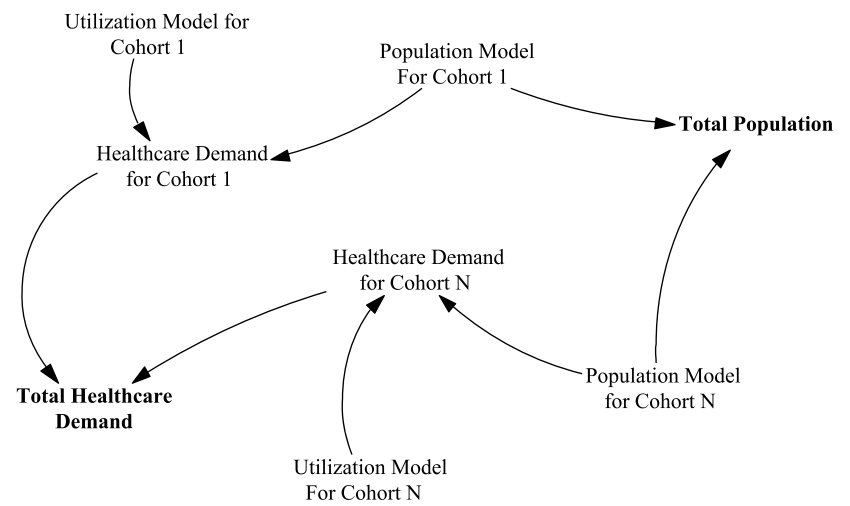

FIGURE 1. Casual loop diagram for the integration of cohorts within the utilization model and the population model.

way of a causal loop diagram that captures, at a high level, the relationships among all variables within a single diagram. After this, a more formalized stock and flow model is specified. The stock and flow model embeds equations that specify the rate of population flow to and from a stock that accumulates the population (due to space limitations, the stock and flow models are not included in this article). Tests used to validate the proposed population model include the dimensional consistency and parameter assessment analysis, which are automatically executed by the simulation software.

Once the stock and flow model is built, the model is executed, or simulated, to obtain results of system behavior over time. The main goal of generating these initial simulations results is to compare the simulated behavior of the modeled system with known real-world trend lines. These trend lines, of course, are the behavior of the real-world system. An affinity between simulated behavior over time and known real-world behavior overtime suggests that the model is an approximation of the real-world system. The model's parameters are further calibrated to generate simulated behavior that more closely mimics the real behavior. Once a model adequately reflects the real-world system, the model can be subjected to theorized interventions, or perturbations, intended to see how the simulated behavior changes under these altered constraints.

\section{THE MODEL}

The model in this study is similar to an aging chain whence, after birth, each person progresses from childhood (first stock) to old age (last stock) unless the individual dies and leaves the system. The rate of stock inflow is determined by the lower bound of the range of that stock, whereas the rate of outflow is determined by the upper bound of the range of that stock. For example, individuals must be 18 years of age to flow into the stock of 18- to 24-year-olds, whereas individuals exiting this stock must complete 25 years.

"Total population" is decomposed into the 7 cohorts: $<18,18$ to 24,25 to 34,35 to 44,45 to 54,55 to 64 , and $>64$ years of age. The 3 major population groups included are native citizens, naturalized citizens, and noncitizens. Native citizens consist of those born in the United States, naturalized citizens consist of those not born in the United States but are residents who are naturalized into US citizenship, and noncitizens consist of temporary residents who reside in the United States (eg, temporary workers, dependents of temporary workers, students, business visitors, diplomats, and undocumented residents).

The 2 central objects of interest within this research are the total ambulatory health care demand and the total population. Figure 1 exhibits the causal loop diagram for the integration of cohorts within the 2 primary coupled models (ie, utilization model and population model). "Health care demand for cohort 1 " is logically the product of the size of the population within cohort 1 (noted as stemming from "population model for cohort 1") and the demand for ambulatory health care services (noted as stemming from "utilization model for cohort 1"). In similar fashion, "health care demand for cohort $\mathrm{n}$ " is the product of the population size and utilization for cohorts other than cohort 1. "Total health care demand" is the summation of the ambulatory health care demand from all cohorts. Finally, total population is the summation of the population for all cohorts.

Figure 2 illustrates the general utilization model for an unspecified cohort. The object of interest within this causal model is the ambulatory demand for health care services (noted as "health care services demand of the cohort"). This

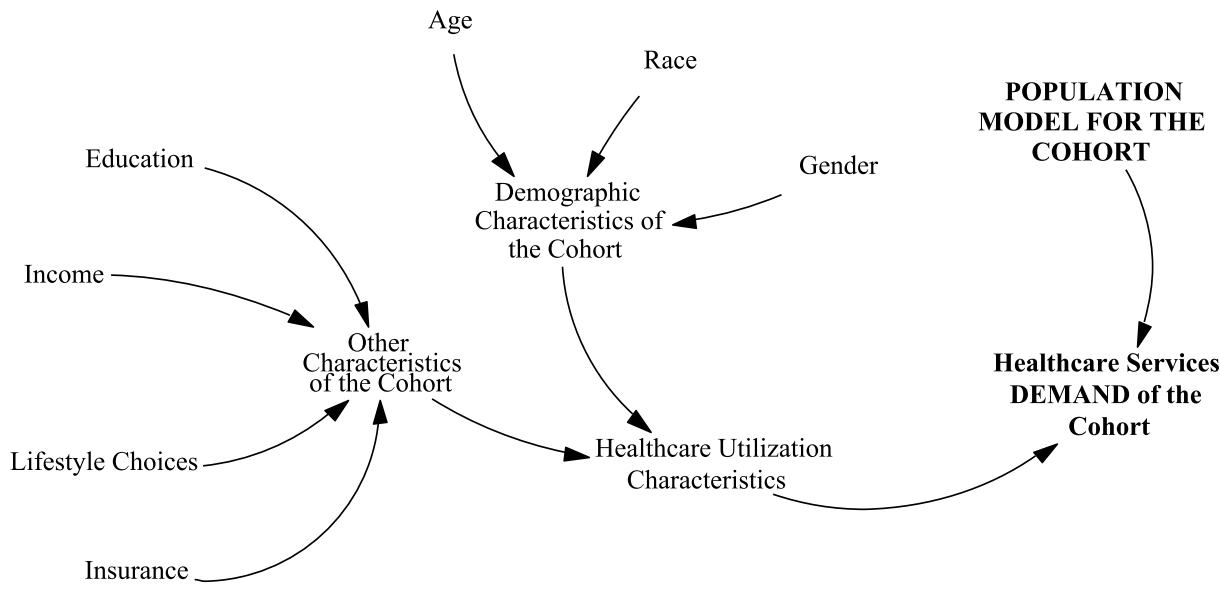

FIGURE 2. Casual loop diagram for the utilization model for an unspecified cohort. 
demand for health care services stems, in part, from population characteristics that help give definition to the variation in health care utilization among the cohort groups. "Age," "race/ethnicity," and "sex" contribute to "demographic characteristics of the cohort," whereas "education," "income," "lifestyle choices," and "insurance" contribute to "other characteristics of the cohort." In conjunction with the utilization, the demand for ambulatory health care services is also a product of the size of the cohort's population, which is treated in the next model.

Figure 3 illustrates the general population model for an unspecified cohort. Notice that, too, the object of interest is the same ambulatory demand for health care services (similarly noted as health care services demand of the cohort). In addition to utilization (discussed previously), the total demand for health care services within a cohort is a function of the size of the population within that cohort (ie, "total population of cohort"). A cohort's population is the summation of the "native citizens," "naturalized citizens," and "noncitizens." Naturally, native citizens, naturalized citizens, and noncitizens are impacted by a "death rate." The "birth rate" contributes to the size of the native citizen population, whereas "emigration," spurred by "economic growth," contributes to the size of the noncitizen population. Economic growth also fuels the path to permanent residency and the size of the naturalized citizen population. Some of the noncitizen population may eventually gain permanent residency, whereas some others may choose to depart from the United States on a permanent basis. The concept that deals with the number of people advancing to the next age group as a product of the present population and the probability that these individuals will live through the interval is captured by "age distribution of the population." The age distribution of the population depends on the birth rates and the death rates of the native population. The people of any age group may immigrate or be naturalized, which adds another factor to the age distribution of the overall population.

\section{DATA RETRIEVAL AND INPUT MODELING}

Numerous formulations in system dynamics simulation models involve nonlinear functions. Occasionally, these functions are specified analytically (ie, mathematical expressions generated from regression analysis to serve as input to the model). However, more frequently, nonlinear relations are captured and portrayed using table functions. These relations are conceived as tables of values for the independent and dependent variables. ${ }^{20}$ Linear interpolation is used for values between the specified points in which information and values for linear and nonlinear relationships are specified. Some inputs are drawn from looking up tables; and some, from defining the mathematical expression by way of statistical tools.

The model uses real birth and death data from the National Center for Health Statistics, Centers for Disease Control and Prevention, ${ }^{39}$ for progression rates among cohort groups. Data on office-based primary care physicians were obtained from the National Ambulatory Medical Care Survey (NAMCS), which is based on a sample of visits to nonfederal-employed office-based physicians who are principally involved in direct patient care activities. Utilization and provision data for ambulatory care services in hospital emergency and outpatient departments were obtained from the National Hospital Ambulatory Medical Care Survey (NHAMCS). Similar to the NAMCS data, the NHAMCS data are rooted in a national sample of visits to emergency departments and outpatient departments of noninstitutional general and short-stay hospitals. Both surveys were provided by the Centers for Disease Control and Prevention. ${ }^{40}$ The birth data used in the model construction were obtained from the Centers for Disease Control and Prevention, Vital Statistics of the United States. ${ }^{41}$ The average death rate data for each age group were obtained from the Centers for Disease Control and Prevention ${ }^{39}$ and used to model the outflow rate due to death for each age group. Because the focus of this article is ambulatory care, only considered are emergency department visits that did not

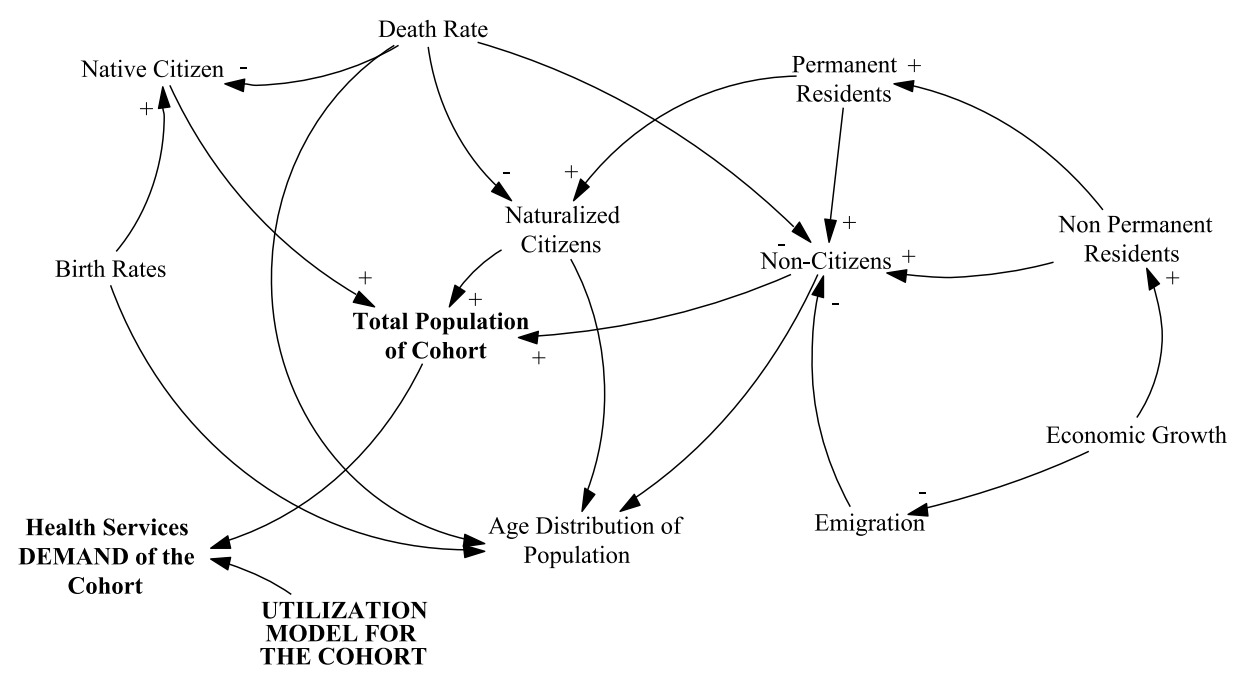

FIGURE 3. Casual loop diagram for the population model for an unspecified cohort. 
Table 1. Percent Error Between Actual and Simulated Population Values

\begin{tabular}{cccc}
\hline Year & $\begin{array}{c}\text { Actual Population-Current } \\
\text { Population Survey }\end{array}$ & $\begin{array}{c}\text { Simulated } \\
\text { Population }\end{array}$ & $\begin{array}{c}\text { Percent } \\
\text { Deviation }\end{array}$ \\
\hline 2003 & $288,280,000$ & $288,197,000$ & -0.03 \\
2004 & $291,166,000$ & $291,272,000$ & 0.04 \\
2005 & $293,834,000$ & $294,663,000$ & 0.28 \\
2006 & $296,824,000$ & $298,005,000$ & 0.40 \\
2007 & $299,106,000$ & $301,132,000$ & 0.68 \\
2008 & $301,483,000$ & $303,827,000$ & 0.77
\end{tabular}

result in hospital admission. Those that show no thirdparty payer (ie, self-pay, no charge, or charity) are classified as "uninsured," and those that show third-party payer (ie, private insurance) are classified as "insured." ${ }^{42}$ Other methods of remittance for services such as Medicare and Medicaid are excluded. Population data were obtained from the Current Population Survey (CPS) conducted by the US Census Bureau (2011). Together, these data sources allow us to calculate the average, per person ambulatory visit rate.

The analysis is performed using SAS 9.2 software as per guidelines given by Nawar. ${ }^{43}$ The per capita visit rates for years 2003 to 2008 are obtained from the statistical analysis of the NAMCS/NHAMCS data. The statistical analysis resulted in the estimation of the mean and the SD of the per capita visit rate for each race and each year under consideration. A sample of per capita visit rate is obtained for each cohort under consideration using these parameters and assuming normality. These samples are then used as inputs to the simulation model such that estimates of total visits for ambulatory care per year by each cohort can be produced. Several studies that deal with the per capita visit rate have shown the extent to which these means and SDs are stable over decades. For example, Stoddard et $\mathrm{al}^{44}$ analyzed health insurance status and ambulatory care for children, Lieu et $\mathrm{al}^{45}$ analyzed race and access to ambulatory care among US adolescents, and Kaufman et $\mathrm{al}^{46}$ considered patterns of medication use in the ambulatory adult population.

The naturalized citizen population corresponds to people who were not born in the United States but gained US citizenship at a later point. The model for naturalized citizens is similar to that of native citizens. However, the 2 ways in which inflows in stocks occur are either through the aging of the younger population or through new naturalizations. As for the native citizens, the outflows in each stock occur through death or aging out. The same death rates used for native citizens are assumed for the naturalized citizens. The data for the number of naturalized by year and age are obtained from the Office of Immigration Statistics within the Department of Homeland Security. ${ }^{47}$ The initial stocks for naturalized citizens by year and age are obtained from the CPS within the US Census Bureau. ${ }^{48}$

The noncitizen population includes people who are not US citizens but may be permanent. The mechanics of this representation is similar to the characterizations used earlier with different inflows and outflows. The initial stock data for noncitizens by age and year are obtained from the Census Bureau CPS. ${ }^{48}$ Permanent residence corresponds to the main inflow for this stock. The data for permanent residency granted each year by age are obtained from the Office of Immigration Statistics within the Department of Homeland Security. ${ }^{47}$ The flow of temporary visa holders is the second inflow. These data are obtained from the Yearbook of Immigration Statistics within the Department of Homeland Security. ${ }^{49}$ A compensation factor of $85 \%$ is assumed to convert the arrival events into inflow information because these data represent arrivals and not individuals.

The next inflow is that of undocumented immigrants. Although estimates of the stock are available, information regarding inflow and outflow is not available. However, inflows and outflows of undocumented populations have been strongly associated with the US economic business cycles. ${ }^{50} \mathrm{~A}$ regression analysis is performed between the change in the undocumented population and the gross domestic product (GDP). Analysis with available data shows that the year-over-year change in stock of these populations is highly correlated $\left(R^{2}=0.91\right)$ to the GDP and is significant $(P<0.05$ and $\mathrm{F}=19.80)$. A regression relation is established between the change in stock and the GDP as follows: change in the stock of undocumented immigrants $=-101,134+$ $322,268 \times$ GDP.

Similar to the native and naturalized citizen outflows, the main outflows from this stock are due to death. This outflow is based on the death rates for different age groups. A second outflow is the outflow due to naturalization of noncitizens, which is modeled from the data used previously. Last, the third outflow consists of temporary visitors who depart the nation after finishing their business or completing their stay.

\section{RESULTS}

The model was executed for a 5-year period (2003-2008) with initial values beginning in 2003, thus generating a simulated 5 -year projection of the total population requiring ambulatory services. Because we have real-world data for the demand for ambulatory services over this same period, we can compare the simulated data generated by our constructed

Table 2. Ratio of Cohort Population to Total Population in the Age Group of 18 to 24 Years

\begin{tabular}{ccccccc}
\hline Year & Insured Whites & Insured African Americans & Insured Hispanics & Uninsured Whites & Uninsured African Americans & Uninsured Hispanics \\
\hline 2003 & 0.43797 & 0.06110 & 0.06818 & 0.13794 & 0.04367 & 0.08974 \\
2004 & 0.43031 & 0.06634 & 0.06345 & 0.13978 & 0.04370 & 0.09047 \\
2005 & 0.42768 & 0.06791 & 0.06319 & 0.14082 & 0.04613 & 0.08740 \\
2006 & 0.42919 & 0.06534 & 0.06432 & 0.13427 & 0.04749 & 0.09136 \\
2007 & 0.42887 & 0.06511 & 0.06694 & 0.13455 & 0.04448 & 0.08310 \\
2008 & 0.42324 & 0.06111 & 0.06947 & 0.13880 & 0.04716 & 0.07934
\end{tabular}


Table 3. Per Capita Ambulatory Health Care Utilization by Cohort Category

\begin{tabular}{|c|c|c|c|c|c|c|}
\hline Year & Insured Whites & Insured African Americans & Insured Hispanics & Uninsured Whites & Uninsured African Americans & Uninsured Hispanics \\
\hline 2003 & 2.366 & 2.125 & 1.508 & 1.294 & 1.248 & 0.686 \\
\hline 2004 & 2.393 & 1.827 & 1.871 & 1.492 & 1.186 & 0.741 \\
\hline 2005 & 2.399 & 1.939 & 1.746 & 1.279 & 0.852 & 0.577 \\
\hline 2006 & 2.275 & 1.701 & 1.984 & 1.330 & 1.354 & 0.786 \\
\hline 2007 & 2.449 & 2.137 & 2.089 & 1.363 & 1.490 & 0.778 \\
\hline 2008 & 2.224 & 2.057 & 2.454 & 1.161 & 1.376 & 0.955 \\
\hline
\end{tabular}

model with the real-world data. Validation of a model as a useful portrayal of the system's demand dynamics rests in part on the degree of congruence between the 2 trend lines. Further calibration of the model can be executed to refine the simulated behavior to more closely fit the actual data; it is possible o manually modify model parameters to achieve a better fit. Table 1 presents the population values from actual and simulated data for this period and the percent errors.

Results show close agreement between the simulated and actual data. The percent error between the two is relatively low, $1.5 \%$ on average, with a decline in agreement between actual and generated data as time progresses. To verify our findings, performed was a regression analysis between simulated and real-world data, showing a high level of agreement [ie, $R^{2}=0.98, P<0.001$ (significant)].

Analysis of population subsets can be performed to further demonstrate the accuracy of the model. Six population cohorts have been purposively selected, including age, race/ethnicity, and insurance coverage. The actual values for these subgroups are taken from Census Bureau CPS. ${ }^{48}$ The population model has been articulated for the entire broader population; this model is not specifically built for the purposively selected cohorts. However, cohorts are easily derived by developing ratios of the cohort of interest to the total population for that group. For example, for 18- to 24-year subgroup, the ratio is obtained by using the CPS. Table 2 displays these ratios. Per capita ambulatory health care utilization by cohort category is then obtained. Table 3 shows the results for the per capita utilization output using the NAMCS and the NHAMCS databases as part of the utilization model.

These results confirm that, among insured 18- to 24-yearolds, the race/ethnicity that uses ambulatory health care the most is white non-Hispanics whereas, in contrast, Hispanics are the least likely to use ambulatory health care. A similar pattern of behavior is also observed for the uninsured.
The actual and simulated volumes of ambulatory visits are presented in Table 4. For raw volume, non-Hispanic whites represent the largest insured group that visited ambulatory centers followed by the African Americans and then by the Hispanics. For the uninsured population, however, Hispanic ambulatory utilization exceeds that of African Americans. In addition, the simulated volume of visits closely resembles the actual data. The percentage deviates between actual and simulated data as presented in Table 5.

The relatively minor gaps between the actual and simulated data indicate that the model is capable of reliably imitating the behavior of the number of visits for the selected cohorts. The largest gap corresponds to insured African Americans for the year 2006, whereas the smallest error is found in the uninsured non-Hispanic white population for the year 2005. A regression analysis, summarized in Table 6, was performed to verify the level of agreement between the simulated and actual data for this cohort. Initially, 4 of the 6 agreements are significant (non-Hispanic insured and African American insured are not significant), but a recalibration process was able to further refine the simulated behavior, presented in Table 7, through optimization procedures that selected parameters and identified the near-best fit. A postadjustment regression analysis demonstrates an $R^{2}$ of 0.79 (significant, $P=0.014$ ) for the non-Hispanic insured cohort and an $R^{2}$ of 0.84 (significant, $P=0.005$ ) for the African American insured.

\section{CONCLUSIONS}

This article has presented simulated ambulatory health care demand trend data for the years 2003 to 2008 by way of a system dynamics modeling approach. The model has a cohort-component structure to it, whereas the overall framework is similar to the structural method. This study chose to differ from most structural models by using

Table 4. Actual and Simulated Volume of Ambulatory Visits for the Studied Cohorts (in Thousands)

\begin{tabular}{|c|c|c|c|c|c|c|c|c|c|c|c|c|}
\hline \multirow[b]{2}{*}{ Year } & \multicolumn{4}{|c|}{ Non-Hispanic White } & \multicolumn{4}{|c|}{ African Americans } & \multicolumn{4}{|c|}{ Hispanics } \\
\hline & Insured & $\begin{array}{l}\text { Simulated } \\
\text { Insured }\end{array}$ & Uninsured & $\begin{array}{l}\text { Simulated } \\
\text { Uninsured }\end{array}$ & Insured & $\begin{array}{l}\text { Simulated } \\
\text { Insured }\end{array}$ & Uninsured & $\begin{array}{l}\text { Simulated } \\
\text { Uninsured }\end{array}$ & Insured & $\begin{array}{c}\text { Simulated } \\
\text { Insured }\end{array}$ & Uninsured & $\begin{array}{l}\text { Simulated } \\
\text { Uninsured }\end{array}$ \\
\hline 2003 & $28,827,957$ & $28,165,900$ & $4,967,318$ & $4,888,410$ & $3,612,982$ & $4,027,630$ & $1,516,638$ & $1,533,180$ & $2,860,848$ & $2,555,220$ & $1,712,689$ & $1,577,820$ \\
\hline 2004 & $28,837,078$ & $26,502,600$ & $5,841,760$ & $6,264,030$ & $3,395,064$ & $3,182,200$ & $1,451,839$ & $1,487,880$ & $3,325,070$ & $3,053,010$ & $1,876,996$ & $1,992,190$ \\
\hline 2005 & $28,689,054$ & $30,046,700$ & $5,035,339$ & $4,757,370$ & $3,682,571$ & $3,317,090$ & $1,099,412$ & 964,160 & $3,085,986$ & $3,332,200$ & $1,409,890$ & $1,341,150$ \\
\hline 2006 & $27,738,803$ & $23,345,200$ & $5,073,794$ & $5,424,800$ & $3,156,152$ & $3,274,500$ & $1,826,155$ & $1,572,730$ & $3,624,597$ & $3,956,230$ & $2,039,043$ & $1,986,560$ \\
\hline 2007 & $29,823,606$ & $28,159,800$ & $5,207,840$ & $5,640,970$ & $3,951,549$ & $3,853,230$ & $1,882,467$ & $2,182,690$ & $3,971,304$ & $3,693,020$ & $1,837,164$ & $1,603,980$ \\
\hline 2008 & $27,009,499$ & $25,484,000$ & $4,623,786$ & $4,646,210$ & $3,606,091$ & $3,750,610$ & $1,861,653$ & $1,880,790$ & $4,891,803$ & $5,255,540$ & $2,172,536$ & $2,437,970$ \\
\hline
\end{tabular}


Table 5. Percent Deviation Between Actual and Simulated

\begin{tabular}{lcccccc}
\hline Year & $\begin{array}{c}\text { White } \\
\text { Insured }\end{array}$ & $\begin{array}{c}\text { White } \\
\text { Uninsured }\end{array}$ & $\begin{array}{c}\text { Black } \\
\text { Insured }\end{array}$ & $\begin{array}{c}\text { Black } \\
\text { Uninsured }\end{array}$ & $\begin{array}{c}\text { Hispanic } \\
\text { Insured }\end{array}$ & $\begin{array}{c}\text { Hispanic } \\
\text { Uninsured }\end{array}$ \\
\hline 2003 & 2.30 & 1.59 & 11.48 & 1.75 & 10.68 & 7.87 \\
2004 & 8.10 & 7.23 & 6.27 & 2.48 & 8.18 & 6.14 \\
2005 & 4.73 & 5.52 & 9.92 & 12.30 & 7.98 & 4.88 \\
2006 & 15.84 & 6.92 & 3.75 & 13.88 & 9.15 & 2.57 \\
2007 & 5.58 & 8.32 & 2.49 & 15.95 & 7.01 & 12.69 \\
2008 & 5.65 & 0.48 & 4.01 & 1.03 & 7.44 & 12.22
\end{tabular}

actual data and empirical relationships. These efforts squarely address some of the criticism of structural models. The results show a close match between simulated and actual values.

In addition to overall utilization projections, an example of simulating a specific subgroup was developed and presented. The population cohorts of this example include men, 18 to 24 years of age, white, African American, and Hispanic, and insurance coverage. Per capita ambulatory health care utilization is estimated. Ratios of population size of each cohort to the respective total population are determined using the CPS. The results show acceptable levels of adherence between simulated and actual values and, thus, confirm that it is feasible to model, with reasonable accuracy, the ambulatory health care utilization of specific population subgroups. It also provides a mechanism to assist in the identification of disparities among groups within the broader populations.

This study makes several contributions. First, this research extends the relatively limited literature on the application of system dynamics to model critical components of the ambulatory health care system. It is asserted that decision makers have to consider a large number of factors and interdependencies that are critical for the performance and sustainability of the health care system. A system dynamics approach offers a logical and intuitive modeling and simulation process that captures these complexities.

Second, the system dynamics framework used to develop the population model presented in this article provides an alternative demand estimation method that explicitly considers interdependencies and feedback loops and the demographic composition and trends of the demand for ambulatory health care services in the United States. As complex enterprises, ambulatory health care institutions value responsiveness for throughput while assuring the safe delivery of quality medical care. Identifying an optimal balance among the competing forces of cost, responsiveness, and quality care in the context of evolving demand by varied patient populations requires tools and approaches that are able to mimic the reality of the system. This provides health

Table 6. Summary of $R^{2}$ and Significance

\begin{tabular}{lccc}
\hline Cohort & Insurance Status & $\boldsymbol{R}^{\mathbf{2}}$ & Significance $\mathbf{F}$ \\
\hline Non-Hispanic white & Insured & 0.40 & 0.174 \\
& Uninsured & 0.85 & 0.009 \\
African Americans & Insured & 0.39 & 0.187 \\
& Uninsured & 0.81 & 0.013 \\
Hispanics & Insured & 0.89 & 0.003 \\
& Uninsured & 0.85 & 0.008
\end{tabular}

Table 7. Actual Versus Simulated Data After Recalibration

\begin{tabular}{cccccc}
\hline & \multicolumn{2}{c}{ Non-Hispanic White } & & \multicolumn{2}{c}{ African Americans } \\
\cline { 2 - 3 } \cline { 5 - 6 } Year & Insured & Simulated Insured & & Insured & Simulated Insured \\
\hline 2003 & $28,827,957$ & $28,695,800$ & & $3,612,982$ & $3,407,200$ \\
2004 & $28,837,078$ & $28,301,900$ & & $3,395,064$ & $3,266,100$ \\
2005 & $28,689,054$ & $29,156,000$ & & $3,682,571$ & $3,579,000$ \\
2006 & $27,738,803$ & $26,979,500$ & & $3,156,152$ & $3,091,600$ \\
2007 & $29,823,606$ & $29,015,000$ & & $3,951,549$ & $4,011,700$ \\
2008 & $27,009,499$ & $26,773,000$ & & $3,606,091$ & $3,730,100$
\end{tabular}

care managers flexibility in the exploration of trade offs among proposed solutions.

Next, an understanding of the influence of different demographic groups on the demand for ambulatory services is essential to the planning for the supply of health care personnel. The results obtained in this article suggest the possibility of quantifying solution configurations based on multiple and dissimilar resources and the relationships among the different components. Using a modeling approach rooted on acknowledging the evolving composition of the population makes possible a more holistic understanding of the forces that create demand for resources.

Last, the model holds the potential to extend a further exploration of the dynamic interactions of other interventions. Thus, it enables a better understanding of how a mix of potential interventions affects the supply and the demand. In addition, the explicit analysis of these interventions can be used as input for sensitivity and elasticity of each intervention relative to both the patient population and the resources used to the deliver health care services.

\section{ACKNOWLEDGMENTS}

The authors thank Dr Nancy Welch, Dr Maureen Boshier, and Mrs Candice Driskell for providing insightful comments and clinical knowledge that substantially strengthens this research.

\section{REFERENCES}

1. Cherry DK, Hing E, Woodwell DA, et al. National Ambulatory Medical Care Survey: 2006 Summary. Hyattsville, MD: National Center for Health Statistics; 2008.

2. Dutton D. Patterns of ambulatory health care in five different delivery systems. Med Care 1979;17:221-243.

3. Cunningham P, Clancy CM, Cohen JW, Wilets M. The use of hospital emergency departments for non-urgent health problems. Med Care Res Rev 1995;52:453-474.

4. Cunningham P. What accounts or differences in the use of hospital emergency departments across U.S. communities? Health Aff (Millwood) 2006;25:w324-w336.

5. Perlino CM. The Public Health Workforce Shortage: Left Unchecked, Will We Be Protected. Washington, DC: American Public Health Association; 2006.

6. Redstone P, Vancura JL, Barry D, Kutner JS. Nonurgent use of the emergency department. J Ambul Care Manage 2008;31:370-376.

7. Weber EJ, Showstack JA, Hunt KA, et al. Are the uninsured responsible for the increase in emergency department visits in the United States? Ann Emerg Med 2008;52:108-115.

8. Fortuna RJ, Robbins BW, Halterman JS. Ambulatory Care Among Young Adults in the United States. Ann Intern Med 2009;151: 379-386. 
9. O’Brien-Pallas L, Baumann A, Donner G, Murphy GT, Lochhaas-Gerlach J, Luba M. Forecasting models for human resources in health care. J Adv Nurs 2000;33:120-129.

10. Derlet RW, Richards JR. Overcrowding in the nation's emergency departments: complex causes and disturbing effects. Ann Emerg Med 2000;35:63-68.

11. Hoot N, Aronsky D. Systematic review of emergency department crowding: causes, effects, and solutions. Ann Emerg Med 2008;52:126-136.

12. Masursky D, Dexter F, O'Leary CE, Applegeet C, Nussmeier NA. Long-term forecasting of anesthesia workload in operating rooms from changes in a hospital's local population can be inaccurate. Anesth Analg 2008;106:1223-1231.

13. Birch S, Kepart G, Tomblin-Murphy G, et al. Human resources planning and the production of health: a needs-based analytical framework. Can Public Policy 2007;33:S1-S16.

14. Hollmann FW, Mulder TJ, Kallan JE. Methodology and Assumptions for the Population Projections of the United States: 1999 to 2100. Washington, DC: US Census Bureau; 2000.

15. O’Neill BC, Balk D, Brickman M, et al. A guide to global population projections. Demogr Res 2001;4:203-288.

16. Pohlmeier W, Ulrich V. An econometric model of the two-part decision-making process in the demand for health care. J Hum Resour 1995;30:339-361.

17. Dubois C-A, McKee M, Nolte E. Analysing trends, opportunities and challenges. In: Human Resources for Health in Europe. Glasgow, United Kingdom: Open University Press, McGraw-Hill Education; 2006:15-40.

18. Roberfroid D, Leonard C, Stordeur S. Physician supply forecast: better than peering in a crystal ball? Hum Resour Health 2009;7:10.

19. van Sonsbeek JM, Gradus RHJM. A microsimulation analysis of the 2006 regime change in the Dutch disability scheme. Econ Model 2006;23:427-456.

20. Sterman JD. Business Dynamics—System Dynamics for a Complex World. Boston, MA: McGraw-Hill Higher Education; 2000

21. Willekens FJ. Demographic forecasting; state-of-the-art and research needs. In: Hazeu CA, Frinking GAB, eds. Emerging Issues in Demographic Research. Burlington, MA: Elsevier Science Publishers; 1990.

22. Wilson T, Phil R. Recent developments in population projection methodology: a review. Popul Space Place 2005;11:337-360.

23. Booth H. Demographic forecasting: 1980 to 2005 in review. Int J Forecast 2006;22:547-581.

24. Turner LA, Ostbye T, Pederson LL. Work force planning in the 90s, part I: efficiency, economy and political will-the need for a new approach. Healthc Manage Forum 1993;6:34-40.

25. Tulpule M, Diaz R, Behr J. Towards an Appropriate Population Model for the United States: A System Dynamics Approach. in MODSIM World 2011. Virginia Beach, VA: NASA; 2011.

26. Groenewold G, Van Ginneken J, De Bruijn B, De Beer J. Estimating mortality with the intercensus cohort component method: application to the Solomon Islands. Population 2007;62:381-414.

27. Batljan I, Thorslund M. The effect of change in educational composition on population ageing. Eur J Ageing 2009;6: 191-200.

28. Swanson DA, Schlottmann A, Schmidt B. Forecasting the population of census tracts by age and sex: an example of the Hamilton-Perry method in action. Popul Res Policy Rev 2010;29:47-63.

29. Samir K, Barakat B, Goujon A, et al. Projection of populations by level of educational attainment, age, and sex for 120 countries for 2005-2050. Demogr Res 2010;22:383-472.

30. Leslie PH. On the use of matrices in certain population mathematics. Biometrika 1945;33:183-212.

31. Ahlburg DA, Lutz W. The need to rethink approaches to population forecasts. Popul Dev Rev 1998;24:1-14.

32. Sanderson WC. Knowledge can improve forecasts: a review of selected socioeconomic population projection models. Popul Dev Rev 1998;24:88-117.

33. Meadows DH, Meadows DL, Rangers J, et al. The Limits to Growth: A Report for the Club of Rome's Project on the Predicament of Mankind. New York, NY: Signet; 1974.

34. Forrester J. World Dynamics. Cambridge, MA: Wright-Allen Press; 1971.

35. Mohapatra PK, Mandal P, Mahanty B. Dynamic modelling for age distribution and age-based policies in manpower planning. Appl Math Model 1992;16:192-200.

36. Azeem Qureshi M. Challenging trickle-down approach; modelling and simulation of public expenditure and human development- the case of Pakistan. Int J Soc Econ 2008;35:269-282.

37. Cohen JE. Should population projections consider "limiting factors"- and if so, how? Popul Dev Rev 1998;24:118-138.

38. Nordhaus WD. World dynamics: measurement without data. Econ J (London) 1973;83:1156-1183.

39. Centers for Disease Control and Prevention, National Center for Health Statistics. Health Data Interactive. Available at: http://www.cdc.gov/nchs/hdi.htm. Accessed 2011.

40. Centers for Disease Control and Prevention. Ambulatory Health Care Data. Available at: http://www.cdc.gov/nchs/ahcd.htm. Accessed 2011.

41. Centers for Disease Control and Prevention. Vital Statistics of the United States. Available at: http://www.cdc.gov/nchs/products/ vsus.htm. Accessed 2011.

42. Centers for Disease Control and Prevention, National Center for Health Statistics. National Health Care Surveys. Available at: http://www.cdc.gov/nchs/dhcs.htm. Accessed 2011.

43. Nawar E. Staff Presentations. Center for Disease Control and Prevention. Ambulatory Health Care Data. Available at: http:// www.cdc.gov/nchs/ahcd/ahcd_presentations.htm. Accessed 2011.

44. Stoddard JJ, St Peter RF, Newacheck PW. Health insurance status and ambulatory care for children. N Engl J Med 1994;330: $1421-1425$.

45. Lieu TA, Newacheck PW, McManus MA. Race, ethnicity, and access to ambulatory care among US adolescents. Am J Public Health 1993;83:960-965.

46. Kaufman DW, Kelly JP, Rosenberg L, Anderson TE, Mitchell AA. Recent patterns of medication use in the ambulatory adult population of the United States. JAMA 2002;287:337-344.

47. Department of Homeland Security, Office of Immigration Statistics. Publications. Available at: http://www.dhs.gov/files/statistics/ publications/. Accessed 2011.

48. US Census Bureau, Current Population Survey, Table Creator. Available at: http://www.census.gov/hhes/www/cpstc/ cps_table_creator.html. Accessed 2011.

49. Department of Homeland Security. Yearbook of Immigration Statistics. Available at: http://www.dhs.gov/files/statistics/publications/ yearbook.shtm. Accessed 2011.

50. Papademetriou DG, Terrazas A. Immigrants and the Current Economic Crisis: Research Evidence, Policy Challenges, and Implications. Washington, DC: Migration Policy Institute; 2009. 